\title{
Mycobacterium chimaera - a new threat for cardiac surgical patients?
}

\author{
Radosław Jaworski ${ }^{1}$, Łukasz Naumiuk ${ }^{2}$, Konrad Paczkowski ${ }^{1}$, Danuta Formella ${ }^{1}$, Renata Pek ${ }^{1}$, \\ Jacek Zieliński ${ }^{3}$, Ireneusz Haponiuk ${ }^{1,4}$ \\ ${ }^{1}$ Department of Pediatric Cardiac Surgery, Copernicus PL Ltd., Gdańsk, Poland \\ 2Laboratory of Clinical Microbiology, University Clinical Center, Gdańsk, Poland \\ ${ }^{3}$ Department of Surgical Oncology, Medical University of Gdansk, Gdańsk, Poland \\ ${ }^{4}$ Department of Physiotherapy, Faculty of Kinesiology and Rehabilitation, University of Physical Education and Sport, Gdańsk, \\ Poland \\ Kardiochirurgia i Torakochirurgia Polska 2017; 14 (1): 22-26
}

\begin{abstract}
An outbreak of invasive Mycobacterium chimaera infections associated with "heater-cooler" devices in patients treated with cardiac surgery has been described worldwide. The authors summarize the current state of knowledge regarding the epidemiology, diagnostics, treatment, and prevention of Mycobacterium chimaera infections in patients after cardiothoracic surgery.

Key words: Mycobacterium chimaera, cardiac surgery, surgical site infections.
\end{abstract}

In 2016, the US Food and Drug Administration (FDA) published recommendations on the use of heater-cooler units (HCUs) with regard to the risk of Mycobacterium chimaera infections in cardiac surgical patients [1]. Similar actions are being taken by other institutions due to the rising incidence of atypical mycobacterial infections in patients undergoing cardiac procedures (Fig. 1). The infections are associated with the intraoperative use of HCUs for controlled hypothermia [2].

Mycobacterium chimaera is a slow-growing nontuberculous mycobacterium belonging to the genus Mycobacterium (Mycobacterium avium complex - MAC). It is generically similar to Mycobacterium intracellulare, as described by Tortoli et al. in 2004 [3]. Mycobacterium chimaera is mostly responsible for pneumonia in patients with conditions of the respiratory system, mucoviscidosis, or immune deficits. Infections of the bones and skin have also been reported [3-5]. Postoperative infections are characterized by late clinical manifestation (the onset of the symptoms may occur as late as several years after the procedure), weak response to treatment, and poor prognosis [6]. The described bacterium occurs mostly in water environments, e.g. in water supply

\section{Streszczenie}

W piśmiennictwie opisuje się kolejne przypadki występowania zakażeń o etiologii Mycobacterium chimaera związanych ze stosowaniem jednostek typu heater-cooler u pacjentów leczonych kardiochirurgicznie. W związku z wykrywaniem infekcji w kolejnych krajach coraz powszechniej mówi się o epidemii. W niniejszym opracowaniu autorzy starają się podsumować obecny stan wiedzy dotyczący epidemiologii, diagnostyki, leczenia i profilaktyki zakażeń o etiologii M. chimaera u chorych leczonych kardiochirurgicznie.

Słowa kluczowe: Mycobacterium chimaera, kardiochirurgia, zakażenia miejsca operowanego.

installations. Identifying $M$. chimaera requires the use of molecular diagnostics consisting of 165 ribosomal RNA (rRNA) gene sequencing [2]. The first reports concerning extrapulmonary $M$. chimaera infections in cardiac surgical patients were published in 2013. Achermann et al. (from Switzerland) described patients undergoing cardiac surgical procedures in 2011 and 2012 who were diagnosed with, respectively, invasive prosthetic mitral valve endocarditis and sepsis with infection manifesting in multiple organs; both conditions were caused by $M$. chimaera [7]. The attention of the researchers was drawn to the occurrence of the very rare infections in a relatively short time frame; therefore, diagnostics were extended, and an epidemiological investigation was conducted [7]. Genotyping using the RAPD-PCR technique (random amplification of polymorphic DNA - polymerase chain reaction) demonstrated that the same strain of $M$. chimaera was isolated from both patients. Further investigation revealed that M. chimaera strains were present in the water tanks and circuits of heater-cooler devices [8].

In 2014, the Swiss Federal Office of Public Health informed about patients suffering from M. chimaera infections who had undergone cardiac procedures using con-

Address for correspondence: Radosław Jaworski MD, Department of Pediatric Cardiac Surgery, Copernicus PL Ltd., 1-6 Nowe Ogrody St, 80-803 Gdańsk, Poland, phone: +48 602243 114, e-mail: radicis@go2.pl

Received: 11.02.2017, accepted: 9.03.2017. 


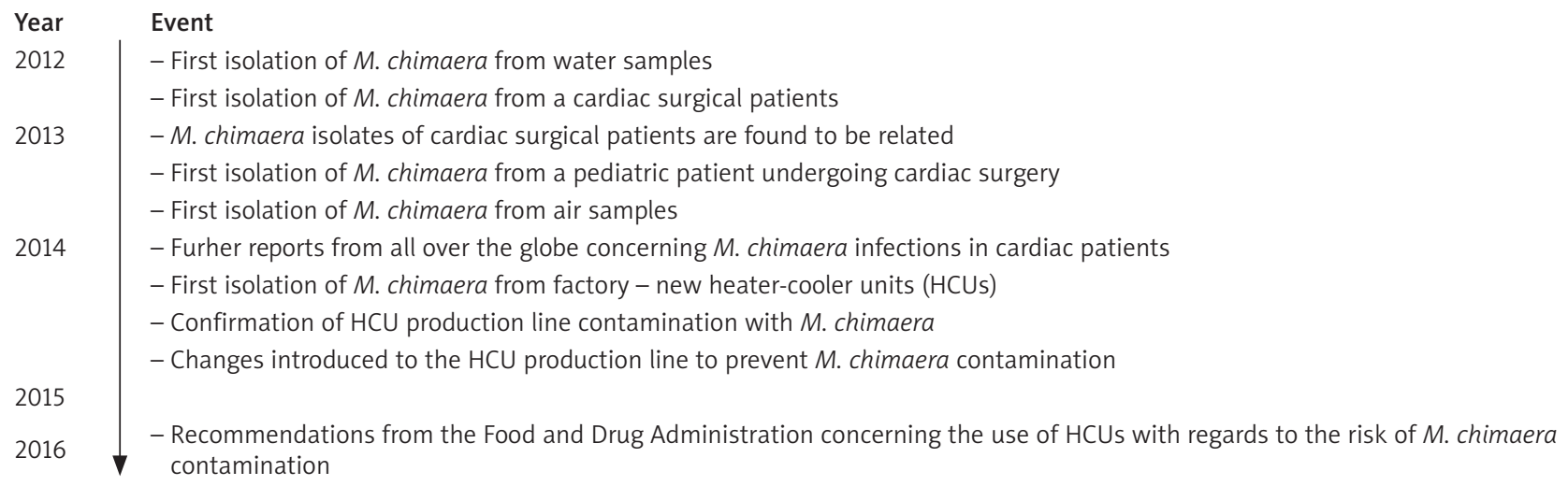

Fig. 1. Timeline of important events related to the study of Mycobacterium chimaera infections in cardiac surgical patients

taminated HCUs [9]. Further reports stated that HCUs from one manufacturer could be contaminated [2, 5, 10-12].

The HCUs are widely used in both adult and pediatric cardiac surgery. They maintain proper temperature of the blood flowing through the extracorporeal circulation machine, ensure proper temperature of cardioplegia, and can be used to control the temperature of warming mattresses. The heatexchange system of an HCU includes a water tank, which may be a reservoir of various microorganisms. Although the water in the device's circuit does not come into direct contact with the patient's blood, there is a possibility that contaminated water may become aerosolized and be vented into the air outside [1]. Studies conducted on the subject proved that $M$. chimaera may be present in the air surrounding the heater-cooler unit; therefore, air is assumed to be the most likely medium of microbial transmission from water to the patient's body during open chest surgery [10, 12, 13].

The first reports concerning remote $M$. chimaera infections in patients treated with cardiac surgery were followed by reports of further patients treated in hospitals worldwide. So far, the available literature includes descriptions of over 70 such cases, and the mortality rate associated with these infections is approximately $50 \%$ despite the use of antibiotic treatment $[11,12]$. A Swiss publication by Sax et al. identified 6 patients in whom the time between the cardiac procedure and clinical manifestation ranged from 1.5 to 3.6 years [2]. The clinical symptoms of $M$. chimaera in this group included fatigability, fever, hepatitis, renal failure, splenomegaly, and pancytopenia [2]. In 5 patients, echocardiographic signs of infective endocarditis (IE) were observed on the cardiac implants. The patients in the described study were treated with a combination of clarithromycin, rifabutin, and ethambutol, combined with either amikacin or moxifloxacin. Three out of the five patients were diagnosed with breakthrough infections with splenic embolism, pacemaker pocket infection, and progressive mitral valve endocarditis. Three patients underwent replacement of the infected valve, and one patient required repeated surgical debridement of the infection site. Two patients died despite antibiotic treatment [2].

In a report by Haller et al. from 2016, describing German experiences with $M$. chimaera in cardiac surgery, infections were observed in 5 patients (age: 53-80) treated in 3 centers [5]. Four of these patients were implanted with prosthetic material, and one underwent coronary artery bypass grafting alone. The times between the cardiac procedure and the manifestation of infection symptoms ranged from 5 months to 5 years. Investigation of heater-cooler units in 78 German cardiac surgery centers demonstrated HCU contamination in 26 cases; however, it should be noted that the findings did not pertain only to $M$. chimaera, but also included other microorganisms such as Pseudomonas aeruginosa, Legionella pneumophila, Stenotrophomonas maltophilia, and fungi [5].

Mycobacterium chimaera infections associated with cardiac surgery mostly affect adult patients; however, Kohler et al. described the first case of such infection in a neonate with a congenital heart defect, who underwent cardiac surgery consisting in aortic coarctation repair with pulmonary artery banding [11]. The child experienced episodes of fever and loss of appetite. The conducted examinations confirmed infection of the prosthetic band and an inflammatory (mycotic) aneurysm of the pulmonary artery. It should be noted that, although the cardiac procedure in the described child was conducted without extracorporeal circulation, microbial transmission from an HCU to the patient's body occurred most likely due to the use of a warming mattress connected to an HCU; this is a common clinical practice in pediatric cardiac surgery, which is also used in our center. Apart from the pediatric patient, Kohler et al. also described the cases of 9 adults with $M$. chimaera infections after cardiac procedures. It is worth noting that the median time from the procedure to the onset of symptoms was 18 months (11-40 months) [11].

In October 2016, American data concerning M. chimaera infections in U.S. patients were updated, identifying 11 patients infected after cardiac surgical procedures [13]. The conducted epidemiological investigation demonstrated that M. chimaera strains isolated from different centers were nearly identical, which provides support for the hypothesis that they may have originated from contaminated HCUs manufactured in a single production plant [13]. These results confirm the observations made by European researchers, who examined samples from 3 centers from different Eu- 
ropean countries and one HCU production plant, coming to the conclusion that the infection originated from HCUs contaminated at the production stage [11, 12, 14]. Independent genetic studies on microorganisms isolated from HCUs in different countries also concluded that the contamination most likely occurred in a single location (a so-called pointsource contamination) during production $[5,13]$.

It should be underscored that the HCU manufacturer remained in constant contact with the users, recommending additional actions concerning the disinfection and sanitation of the devices. These recommendations were also distributed in Poland. Moreover, Haller et al. reported that the HCU manufacturer, on its own initiative, conducted environmental studies at the HCU production plant in August 2014, confirming the contamination of the production line and the water supply system with $M$. chimaera $[1,5]$. In September 2014, the manufacturer introduced cleaning and disinfecting procedures to the production line; the devices manufactured after September 2014 are believed to be free from M. chimaera contamination [1].

To the best of our knowledge, no $M$. chimaera infection has yet been noted in Poland in patients treated with cardiac surgery; nevertheless, the potential risk of this complication should be considered in everyday clinical practice. Until certain and universal methods of preventing HCU contamination and procedures for disinfection and safe use of these devices are established, it seems reasonable to act in accordance with the suggestions of the manufacturers and recommendations issued by reference organizations. The guidelines published by the Centers for Disease Control and Prevention (CDC) and FDA pertain primarily to devices manufactured before September 2014 and stress that the air vented from the HCU should be prevented from coming into contact with the environment of the surgical field $[1,13]$. Also, the device's manufacturer recommends disinfecting the HCUs according to defined procedures. However, Schreiber et al. demonstrated that this may prove ineffective - despite the intensification of disinfection procedures, the contamination of HCUs persisted [15]. The researchers believe that the proliferation of mycobacteria and the development of biofilm in the device can be facilitated by corrosion, characteristics of materials used for HCU production, and so-called dead spaces in the structure of the device.

Additionally, it has been underscored that performing microbiological testing to exclude or confirm HCU contamination is not currently recommended due to the complexity of the required methodology and the high rate of false negative results $[1,16]$. In 2015, the European Centre for Disease Prevention and Control (ECDC) published a detailed methodology for culturing biological materials and performing molecular diagnostics in order to detect $M$. chimaera [8]. These guidelines also include criteria for identifying probable and confirmed cases of M. chimaera infections (Fig. 2) [8].

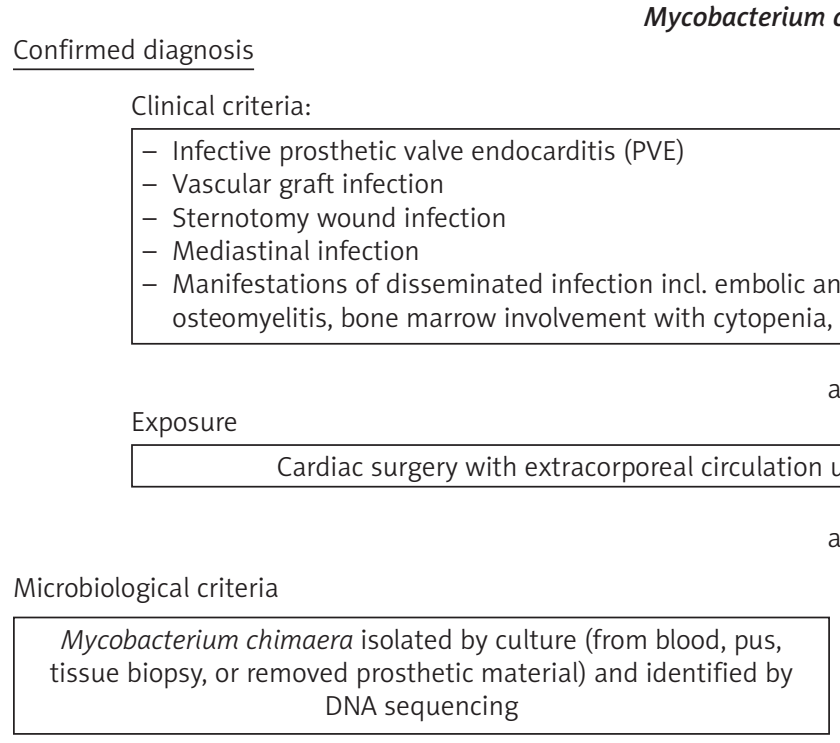

Clinical criteria:

- Infective prosthetic valve endocarditis (PVE)

- Vascular graft infection

- Sternotomy wound infection

Mediastinal infection

Manifestations of disseminated infection incl. embolic and immunological manifestations, e.g. splenomegaly, arthritis, osteomyelitis, bone marrow involvement with cytopenia, nephritis, etc.

and

to 5 years before clinical symptoms of infection

and

Microbiological criteria

Myobacterium chimaera detected by direct polymerase chain reaction $(P C R)$ and amplified DNA sequencing from a sample of blood, pus, tissue biopsy, or removed prosthetic material

or

Mycobacterium avium complex (MAC) detected by culture or
direct PCR from a sample of blood, pus, tissue biopsy or removed
prosthetic material
or
Histopathological detection of non-caseating granuloma or foamy
macrophages with acid-fast bacili in cardiac or vascular tissue in
the proximity of prosthetic materialor in the specimen from the
sternotomy wound

Fig. 2. Criteria for diagnosing Mycobacterium chimaera in cardiac surgical patients according to the European Centre for Disease Prevention and Control [8] 

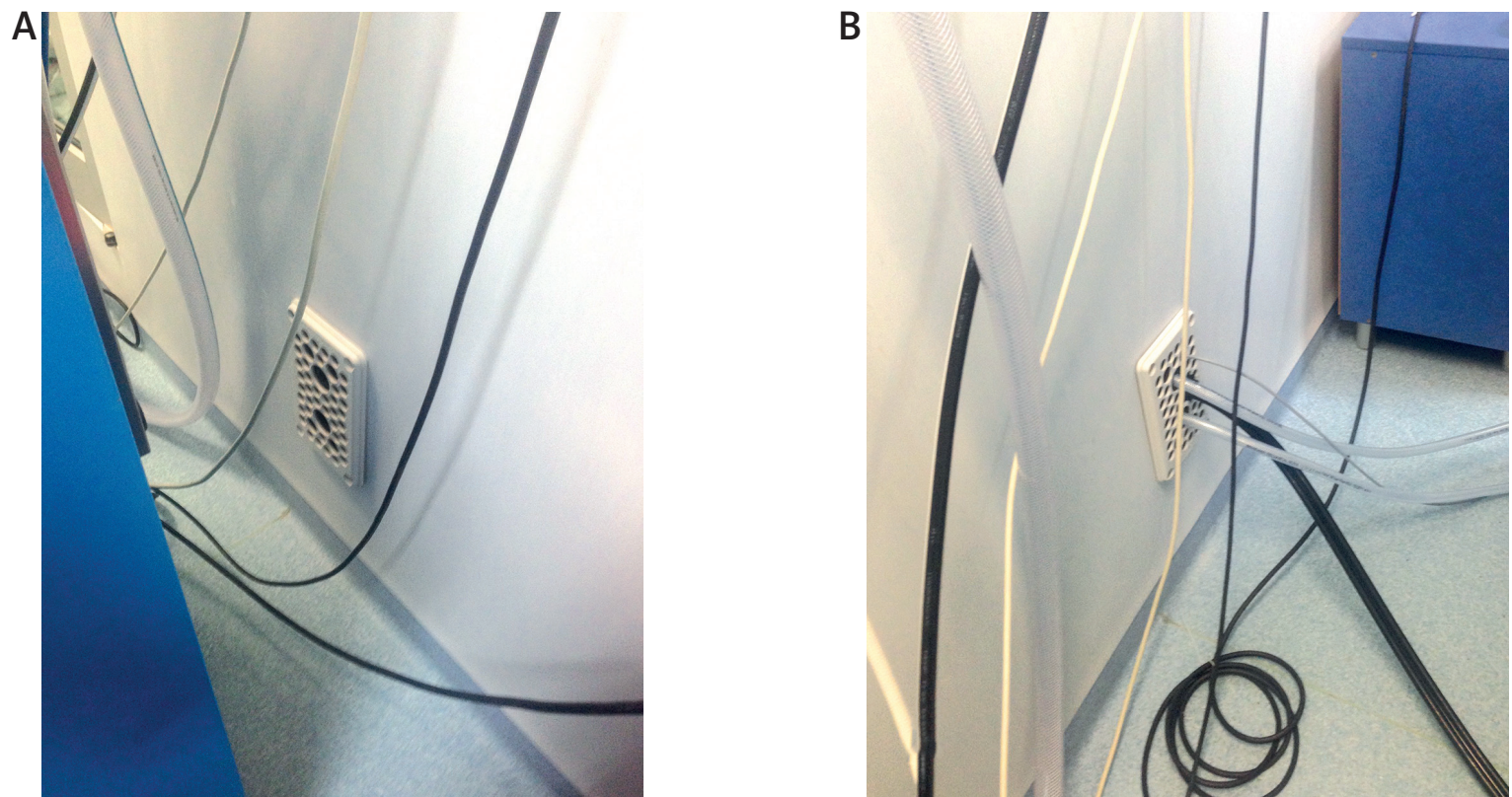

Fig. 3. Modifications made to the operating room on the Pediatric Cardiac Surgery Ward in Gdansk in order to move the heater-cooler unit outside the operating room (A), the control cable and water connections passing through the wall of the operating room (B)

Although the awareness of the medical community regarding $M$. chimaera infections is continuously improving, questions pertaining to the management of patients at risk of these infections, the methods of securing HCUs, and prophylactic actions still require some clarification [2]. As demonstrated by Sommerstein et al., the high risk of microbial transmission through air associated with the use of HCUs is also present in operating rooms adhering to the highest standards of air cleanliness [10]. Therefore, the simplest method of protecting the patient from infection seems to be to completely isolate the environment of the operating room from the air vented by HCUs. This can be achieved by moving the HCU outside the operating room and controlling it remotely. This method usually does not require extensive technical works in the operating theater and is not associated with high expenses. In our center, the HCU was moved outside the operating room, which was done with little expenditure (Fig. 3). Nonetheless, other actions limiting the occurrence of hospital infections at cardiac surgery wards (obtaining microbiological cultures from patients, proper perioperative antibiotic prophylaxis, and hand hygiene) should not be neglected [17-19]. Reorganizing operating rooms to isolate the HCUs can be effective not only in preventing $M$. chimaera infections, but also in preventing wound infections with other pathogens that can hypothetically colonize the heater-cooler devices. This strategy is in accordance with the recommendations of experts and $\mathrm{HCU}$ manufacturers, and it may be useful during the building and reorganizing of operating rooms used for the purposes of cardiac surgery.

In conclusion, it should be underscored that HCUs can be a source of bacterial infections in patients undergoing cardiac surgery [2]. The risk is mostly associated with the use of heater-cooler units manufactured before September
2014, but it seems reasonable to also apply the recommendations from institutions responsible for prevention of infection to all HCUs from all manufacturers as well as to all devices that may generate aerosols in the operating room. The simplest method of preventing surgical field contamination by air vented from an HCU seems to be to move the device outside the operating room and act in accordance with the manufacturer's guidelines. Performing microbiological testing in order to confirm or exclude HCU contamination with $M$. chimaera is not currently recommended. It is advisable to monitor the scientific reports concerning this subject, as the information on $M$. chimaera infections in cardiac surgical patients is updated every few months. In the case of unexplained infections (especially those occurring in the long-term postoperative period) in cardiac surgical patients, the possibility of $M$. chimaera infection should be considered.

\section{Disclosure}

Authors report no conflict of interest.

\section{References}

1. Available at: http://www.fda.gov/MedicalDevices/Safety/AlertsandNotices/ ucm 520191.htm (11.02.2017).

2. Sax H, Bloemberg G, Hasse B, Sommerstein R, Kohler P, Achermann Y, Rös sle M, Falk V, Kuster SP, Böttger EC, Weber R. Prolonged outbreak of Mycobacterium chimaera infection after open-chest heart surgery. Clin Infect Dis 2015; 61: 67-75.

3. Tortoli E, Rindi L, Garcia MJ, Chiaradonna P, Dei R, Garzelli C, Kroppenstedt RM, Lari N, Mattei R, Mariottini A, Mazzarelli G, Murcia MI, Nanetti A, Piccoli P, Scarparo C. Proposal to elevate the genetic variant MAC-A, included in the Mycobacterium avium complex, to species rank as Mycobacterium chimaera sp. nov. Int I Syst Evol Microbiol 2004; 54: 1277-1285.

4. Cohen-Bacrie S, David M, Stremler N, Dubus JC, Rolain JM, Drancourt M. Mycobacterium chimaera pulmonary infection complicating cystic fibrosis: a case report. J Med Case Rep 2011; 5: 473. 
5. Haller S, Höller C, Jacobshagen A, Hamouda O, Abu Sin M, Monnet DL, Plachouras D, Eckmanns T. Contamination during production of heater-cooler units by Mycobacterium chimaera potential cause for invasive cardiovascular infections: results of an outbreak investigation in Germany, April 2015 to February 2016. Euro Surveill 2016; 21: doi: 10.2807/1560-7917.

6. Sommerstein R, Schreiber PW, Diekema DJ, Edmond MB, Hasse B, Marschall J, Sax H. Mycobacterium chimaera outbreak associated with heatercooler devices: piecing the puzzle together. Infect Control Hosp Epidemiol 2017; 38: 103-108.

7. Achermann Y, Rössle M, Hoffmann M, Deggim V, Kuster S, Zimmermann DR, Bloemberg G, Hombach M, Hasse B. Prosthetic valve endocarditis and bloodstream infection due to Mycobacterium chimaera. J Clin Microbiol 2013; 51: 1769-1773.

8. Available at: http://ecdc.europa.eu/en/publications/Publications/EU-protocol-for-M-chimaera.pdf (11.02.2017).

9. Available at: https://www.admin.ch/gov/de/start/dokumentation/medienmittei lungen.msg-id-53774.html (11.02.2017).

10. Sommerstein R, Rüegg C, Kohler P, Bloemberg GV, Kuster SP, Sax H. Transmission of Mycobacterium chimaera from heater-cooler units during cardiac surgery despite an ultraclean air ventilation system. Emerg Infect Dis 2016; 22: 1008-1013.

11. Kohler P, Kuster SP, Bloemberg G, Schulthess B, Frank M, Tanner FC, Ros-sle M, Boni C, Falk V, Wilhelm MJ, Sommerstein R, Achermann Y, ten Oever J, Debast SB, Wolfhagen MJHM, Bruinsma GJBB, Vos MC, Bogers A, Serr A, Beyersdorf F, Sax H, Bottger EC, Weber R, van Ingen J, Wagner D, Hasse B. Healthcare-associated prosthetic heart valve, aortic vascular graft, and disseminated Mycobacterium chimaera infections subsequent to open heart surgery. Eur Heart J 2015; 36: 2745-2753.
12. Sommerstein R, Schreiber PW, Diekema DJ, Edmond MB, Hasse B, Marschall J, Sax H. Mycobacterium chimaera outbreak associated with heatercooler devices: piecing the puzzle together. Infect Control Hosp Epidemiol 2017; 38: 103-108.

13. Perkins KM, Lawsin A, Hasan NA, Strong M, Halpin AL, Rodger RR, MoultonMeissner H, Crist MB, Schwartz S, Marders J, Daley CL, Salfinger M, Perz JF. Notes from the Field. Mycobacterium chimaera contamination of heatercooler devices used in cardiac surgery - United States. MMWR Morb Mortal Wkly Rep 2016; 65: 1117-1118.

14. Gotting T, Klassen S, Jonas D, Benk C, Serr A, Wagner D, Ebner W. Heatercooler units: contamination of crucial devices in cardiothoracic surgery. J Hosp Infect 2016; 93: 223-228.

15. Schreiber PW, Kuster SP, Hasse B, Bayard C, Rüegg C, Kohler P, Keller PM, Bloemberg GV, Maisano F, Bettex D, Halbe M, Sommerstein R, Sax H. Reemergence of Mycobacterium chimaera in heater-cooler units despite intensified cleaning and disinfection protocol. Emerg Infect Dis 2016; 22: 1830-1833.

16. Available at: https://emergency.cdc.gov/han/han00397.asp (11.02.2017).

17. Jaworski R, Haponiuk I, Steffens M, Arlukowicz E, Irga-Jaworska N, Chojnicki M, Kwasniak E, Zielinski J. Colonization of multidrug resistant pathogens in a hybrid pediatric cardiac surgery center. Arch Med Sci 2016; 12: 639-644.

18. Jaworski R, Haponiuk I, Irga-Jaworska N, Chojnicki M, Steffens M, Paczkowski K, Zielinski J. Fungal infections in children in the early postoperative period after cardiac surgery for congenital heart disease: a single-centre experience. Interact Cardiovasc Thorac Surg 2016; 23: 431-437.

19. Jaworski R, Haponiuk I, Chojnicki M, Irga N, Wisniewska B, Treder E, Ziołkowska I, Steffens M, Zielinski J. Programme to improve hand hygiene in a paediatric cardiac surgery department. Kardiochir Torakochir Pol 2012; 12: $278-282$. 